\title{
Combined effects on leukemia cell growth by targeting sphingosine kinase 1 and sirtuin 1 signaling
}

\author{
YUXIANG LI ${ }^{1}$, YUXIA GAO ${ }^{1}$, BING LIANG ${ }^{1}$, WENBO NIE ${ }^{1}$, LIJING ZHAO ${ }^{1}$ and LISHENG WANG ${ }^{1,2}$ \\ ${ }^{1}$ School of Nursing, Jilin University, Changchun, Jilin 130021; ${ }^{2}$ Department of Molecular Diagnosis and \\ Regenerative Medicine, The Affiliated Hospital of Qingdao University, Qingdao, Shandong 266000, P.R. China
}

Received August 31, 2019; Accepted September 8, 2020

DOI: $10.3892 /$ etm.2020.9392

\begin{abstract}
Targeting multiple signaling pathways is a potential novel therapeutic strategy for the treatment of leukemias. Leukemia cells express high levels of sphingosine kinase 1 (Sphk1) and sirtuin 1 (SIRT1). However, to the best of our knowledge, their interaction and potential synergistic inhibitory effects on the growth and survival of leukemia cells have not been investigated. The present study revealed the role of the Sphk1/S1P/SIRT1 axis in K562, KCL22 and TF1 cells and hypothesized that the inhibition of Sphk1 and SIRT1 had synergistic effects on the growth and survival of leukemia cells. Cell viability was tested using a Cell Counting Kit- 8 assay and cell colony forming assay. Cell apoptosis was detected using Annexin V-APC/PI staining. The stages of the cell cycle were measured using PI staining. Protein levels were measured by western blotting. Treatment of leukemia cells with S1P resulted in the upregulation of SIRT1 expression, whereas inhibition of Sphk1 induced SIRT1 downregulation in leukemia cells. Both SKI-II and EX527 actively suppressed growth, blocked cell cycle progression and induced apoptosis of leukemia cells. Furthermore, inhibition of Sphk1 and SIRT1 exhibited suppressive effects on the growth and survival of leukemia cells. Notably, the inhibition of Sphk1 and SIRT1 suppressed cell growth and induced apoptosis of T-315I mutation-harboring cells. Additionally, treatment with SKI-II and EX527 suppressed the ERK and STAT5 pathways in leukemia cells. These data indicated that targeting the Sphk1/S1P/SIRT1 axis may be a novel therapeutic strategy for the treatment of leukemia.
\end{abstract}

\section{Introduction}

Chronic myeloid leukemia (CML) is a myeloproliferative disorder caused by BCR-ABL-induced hematopoietic stem

Correspondence to: Professor Lisheng Wang, School of Nursing, Jilin University, 965 Xinjiang Street, Changchun, Jilin 130021, P.R. China

E-mail: lishengwang@ymail.com

Key words: sphingosine kinase 1, sirtuin 1, leukemia, suppression, signaling cell transformation (1). Although tyrosine kinase inhibitor (TKI) therapy has successfully improved the long-term survival rates of patients with CML (2), certain patients relapse due to TKI resistance (3). BCR-ABL tyrosine kinase constitutively activates multiple signaling pathways, such as the PI3K/AKT/mTOR and JAK-STAT signaling pathways, that dysregulate cell cycle progression, transforms hematopoietic stem cells and induces drug resistance $(4,5)$. Therefore, targeting multiple pathways may provide novel therapeutic effects for overcoming TKI resistance (6).

Dysregulation of lipid metabolism has been demonstrated to be a major event in the progression of various types of cancer, including hematopoietic malignancies (7-10). Sphingosine 1-phosphate (S1P) is a bioactive sphingolipid metabolite that mediates diverse cellular processes, including cell proliferation, survival and migration $(9,11)$. Sphingosine kinase (Sphk) phosphorylates sphingosines to generate S1P and is a critical signal regulator of sphingolipid metabolism (12). There are two isoforms of Sphk: Sphk1 and Sphk2 (13). Sphk1 overexpression and aberrant activation have been detected in various types of cancer, including hematopoietic malignancies such as leukemia and multiple myeloma $(14,15)$. Extracellular stimuli and numerous genetic mutations, including Fms-like tyrosine kinase 3 (FLT3), Kit receptor tyrosine kinase and BCR-ABL fusion protein, aberrantly activate the Sphk1/S1P pathway in leukemia cells (15-20).

In CML, the Sphk1/S1P pathway mediates BCR/ABL activation-induced Mcl-1 upregulation (16). Furthermore, activation of Sphk1 contributes to imatinib resistance by modulating protein phosphatase 2A (17). Previous studies have revealed that targeting Sphk1 induces Mcl-1-dependent cell death in acute myeloid leukemia (21) and inhibition of the Sphk1/S1P axis is considered to be novel approach to overcome drug resistance (22). These previous studies support the hypothesis that Sphk1 is a novel therapeutic target for the treatment of leukemia (15).

SIRT1 is a nicotine adenine dinucleotide-dependent protein deacetylase which directly links transcriptional regulation to intracellular energy and is involved in the coordination of several distinct cellular functions, including cell survival, apoptosis and metabolism (23). SIRT1 is significantly increased in leukemia stem cells and promotes leukemia development (24). Furthermore, SIRT1 activation promotes the maintenance and drug resistance of human FLT3-internal tandem duplication in acute myeloid leukemia stem cells (25). Inhibition of SIRT1 
induces G1 arrest, apoptosis and inhibits the proliferation of acute myeloid gene 1 and myeloid transforming gene 8)-positive cells (26). Furthermore, targeting SIRT1 induces CML sensitivity to TKI treatment via the activation of p53 (27). Therefore, SIRT1 inhibition may be a promising novel approach for the ablation of leukemia stem cells in leukemia therapy $(25,28)$.

Previous research elucidated that SIRT1 mediated Sphk1/S1P-induced neovascularization, including the proliferation and migration of endothelial cells (13). Given the important regulatory roles of Sphk1/S1P in leukemogenesis, it was hypothesized that Sphk1 and SIRT1 may interact in leukemia cells and targeting them may offer a novel and effective therapeutic approach. The present study validated that the Sphk1/S1P/SIRT1 axis is activated in CML cell lines and investigated the effects of Sphk1 and SIRT1 inhibition on the growth, survival and drug resistance of leukemia cells, which provided the basis of combined suppressive effects by targeting dual molecules in leukemia cells.

\section{Materials and methods}

Leukemia cell lines and inhibitors. The human leukemia cell lines K562 and KCL22 were cultured in RPMI-1640 medium (Gibco; Thermo Fisher Scientific, Inc.) supplemented with 10\% FBS (HyClone; Cytiva). TF-1 cells were obtained from America Type Culture Collection and transduced with miGR1-BA-T315I retroviral vectors to establish the imatinib-resistant cell line TF-1-T315I. These cells were cultured in RPMI-1640 medium supplemented with 10\% FBS and $5 \mathrm{ng} / \mathrm{ml}$ GM-CSF (Sigma-Aldrich; Merck KGaA). The Sphk1-specific inhibitors DMS (Sigma-Aldrich; Merck KGaA) and SKI-II (Sigma-Aldrich; Merck KGaA), and the SIRT1-specific inhibitor EX527 (MedchemExpress) were dissolved in DMSO.

Cell growth assay. The cell growth assay was performed using a Cell Counting Kit-8 (CCK-8; Dojindo Molecular Technologies, Inc.) according to the manufacturer's instructions, which stains living cells. K562, KCL22 or TF-1-T315I cells were seeded into 96 -well plates $\left(5 \times 10^{3}\right.$ cells/well) in $100 \mu \mathrm{l}$ of culture medium and treated with DMSO, SKI-II $(5,10$ or $20 \mu \mathrm{M}), \operatorname{EX527}(5,10$ or $20 \mu \mathrm{M})$ or SKI-II $(20 \mu \mathrm{M})$ $+\operatorname{EX527}(20 \mu \mathrm{M})$ for 24 or $48 \mathrm{~h}$. Subsequently, the cells were incubated with $10 \mu \mathrm{l}$ of CCK-8 reagent in a $5 \% \mathrm{CO}_{2}$ atmosphere at $37^{\circ} \mathrm{C}$ for $3 \mathrm{~h}$ and the optical density at $450 \mathrm{~nm}$ was measured on Varioskan Flash (Thermo Fisher Scientific, Inc.). All experiments were performed in triplicate.

Cell colony forming assay. K562 or TF-1-T315I cells were seeded in triplicate in 24 -well plates $\left(5 \times 10^{2}\right.$ cells/well $)$ and cultured in $1 \%$ methylcellulose medium (Beijing Solarbio Science \& Technology Co., Ltd.) containing 10\% FBS supplemented with or without $5 \mathrm{ng} / \mathrm{ml}$ GM-CSF. The cells were then treated with DMSO, $20 \mu \mathrm{M}$ EX527, $20 \mu \mathrm{M}$ SKI-II or $20 \mu \mathrm{M}$ EX527 $+20 \mu \mathrm{M}$ SKI-II. Following 7 days of culturing at $37^{\circ} \mathrm{C}$, the number of colonies ( $>50$ cells) were counted using an inverted light microscope (Olympus Corporation) under normal light at $\mathrm{x} 40$ magnification.

Cell cycle analysis. TF-1-T315I cells were seeded into 12-well plates ( $1 \times 10^{5}$ cells/well) and cultured in RPMI-1640 medium containing 10\% FBS supplemented with $5 \mathrm{ng} / \mathrm{ml} \mathrm{GM-CSF}$. Then, DMSO, $20 \mu \mathrm{M}$ EX527, $20 \mu \mathrm{M}$ SKI-II or $20 \mu \mathrm{M}$ EX527 $+20 \mu \mathrm{M}$ SKI-II were added to the medium. Following incubation in a $5 \% \mathrm{CO}_{2}$ atmosphere at $37^{\circ} \mathrm{C}$ for $24 \mathrm{~h}$, cells were collected, washed with PBS and fixed in ice-cold 70\% ethanol overnight at $-20^{\circ} \mathrm{C}$. Cells were washed with PBS and stained with $20 \mu \mathrm{g} / \mathrm{ml}$ propidium iodide (PI; BD Biosciences) at $4^{\circ} \mathrm{C}$ in the dark for $30 \mathrm{~min}$. Data were acquired on a FACSCalibur (BD Biosciences) and analyzed using FlowJo software version 7.6 (Becton-Dickinson \& Company).

Cell apoptosis assay. K562, KCL22 or TF-1-T315I cells were plated in 12-well plates $\left(1 \times 10^{5}\right.$ cells/well $)$ and cultured in RMPI-1640 medium containing 10\% FBS supplemented with or without $5 \mathrm{ng} / \mathrm{ml} \mathrm{GM-CSF}$. Subsequently, the cells were treated with DMSO, $20 \mu \mathrm{M}$ EX527, $20 \mu \mathrm{M}$ SKI-II or $20 \mu \mathrm{M}$ EX527 $+20 \mu \mathrm{M}$ SKI-II. After culturing in a $5 \% \mathrm{CO}_{2}$ atmosphere at $37^{\circ} \mathrm{C}$ for $24 \mathrm{~h}$, the cells were collected, washed with PBS and suspended in $100 \mu \mathrm{l}$ of $1 \mathrm{X}$ binding buffer containing $5 \mu \mathrm{l}$ of Annexin V-APC (eBioscience; Thermo Fisher Scientific, Inc.). Following incubation at room temperature for $20 \mathrm{~min}$, samples were stained with PI at room temperature in the dark for $15 \mathrm{~min}$ and detected by FACSCalibur (BD Biosciences) within $1 \mathrm{~h}$. The data were analyzed using FlowJo software version 7.6 (Becton-Dickinson \& Company).

Lentivirus transduction. TF1 cells were plated in six-well plates ( $2 \times 10^{5}$ cells/well) and transduced with lentiviral vectors encoding BCR-ABL1 (T315I) or control vectors at a multiplicity of infection of 20. The mutant BCR-ABL transduction efficiency of lentiviral vectors, as indicated by GFP expression, was detected by the intensity of green fluorescence at FITC channel on FACSCalibur (BD Biosciences). The data were analyzed using FlowJo software version 7.6 (Becton-Dickinson \& Company).

Western blotting. K562 cells were treated with DMSO, S1P $(0.5,1,1.5$ or $2 \mu \mathrm{M}$ for $8 \mathrm{~h}$ or $1 \mu \mathrm{M}$ for $2,4,8,12$ or $24 \mathrm{~h})$, DMS $(5,10$ or $20 \mu \mathrm{M}$ for $24 \mathrm{~h})$, EX527 (5, 10, 20 or $40 \mu \mathrm{M}$ for $24 \mathrm{~h})$, SKI-II $(20 \mu \mathrm{M}$ for $24 \mathrm{~h})$ or SKI-II + EX527 $(20 \mu \mathrm{M}$ EX527 and $20 \mu \mathrm{M}$ SKI-II for $24 \mathrm{~h}$ ). TF-1-T315I cells were treated with DMSO, EX527 (5, 10, 20 or $40 \mu \mathrm{M}$ for $24 \mathrm{~h})$, SKI-II $(20 \mu \mathrm{M}$ for $24 \mathrm{~h}$ ) or SKI-II + EX527 (20 $\mu \mathrm{M}$ EX527 and $20 \mu \mathrm{M}$ SKI-II for $24 \mathrm{~h}$ ). Following this, the cells were washed twice with $1 \mathrm{X}$ PBS and proteins were extracted from cells by suspension in RIPA buffer (Sigma-Aldrich; Merck KGaA) containing PMSF (Sigma-Aldrich; Merck KGaA) and 1\% phosphatase inhibitors (Sigma-Aldrich; Merck KGaA). Lysates were clarified by centrifugation at $12,000 \mathrm{x} \mathrm{g}, 4^{\circ} \mathrm{C}$ for $30 \mathrm{~min}$ and total protein was determined using a BCA protein assay kit (Thermo Fisher Scientific, Inc.). Then, $30 \mu \mathrm{g}$ of sample protein was separated by $12 \%$ SDS-PAGE and transferred to PVDF membranes. Following blocking with 5\% non-fat dry milk in TBS with $0.05 \%$ Tween-20 at room temperature for $2 \mathrm{~h}$. The membranes were incubated with primary antibodies against SIRT1 (cat. no. 2496; 1:1,000 dilution; Cell Signaling Technology, Inc.), ERK (cat. no. 4695; 1:1,000 dilution; Cell Signaling Technology, Inc.), phosphorylated (p-)ERK (cat. no. 9101; 1:1,000 dilution; Cell Signaling Technology, Inc.), STAT5 (cat. no. 25656; 1:1,000 dilution; Cell Signaling Technology, Inc.), p-STAT5 (cat. no. 9359; 1:1,000 dilution; 
A

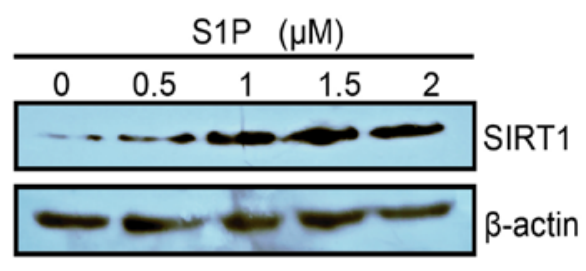

B

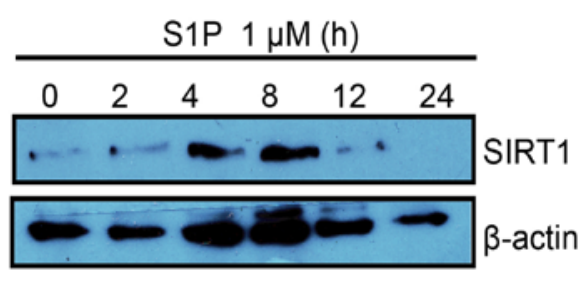

C

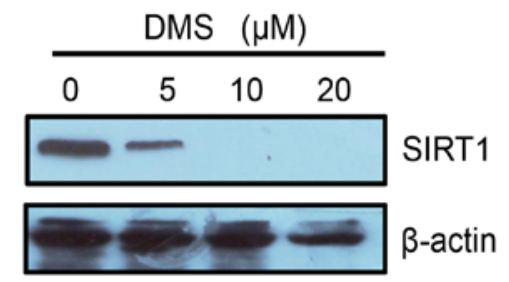

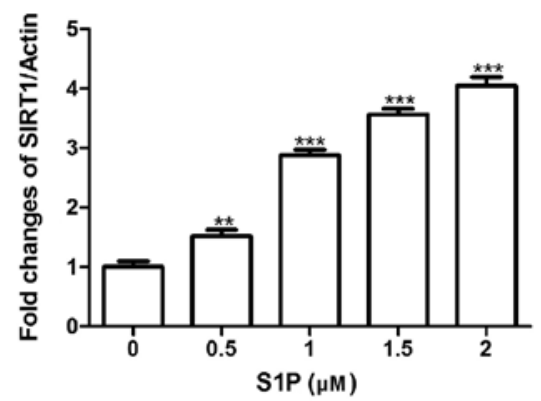
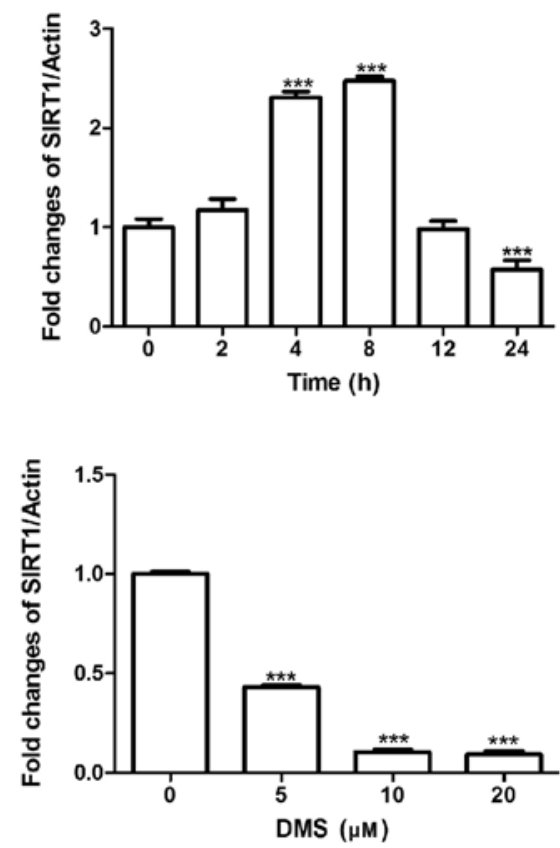

Figure 1. Sphingosine kinase 1/S1P upregulates SIRT1 expression in leukemia cells. (A) K562 cells were treated with S1P (0, $0.5,1,1.5$ or $2 \mu \mathrm{M})$ for 8 h. (B) K562 cells were treated with $1 \mu \mathrm{M} \mathrm{S1P}$ for various time-points $(0,2,4,8,12$ or $24 \mathrm{~h})$. (C) K562 cells were treated with DMS $(0,5,10$ or $20 \mu \mathrm{M})$ for $24 \mathrm{~h}$. SIRT1 expression was determined by western blotting. Data are presented as the means \pm standard deviation. ${ }^{* *} \mathrm{P}<0.01$ and ${ }^{* * *} \mathrm{P}<0.001$ compared with $0 \mu \mathrm{M}$ or $0 \mathrm{~h}$. S1P, sphingosine 1-phosphate; SIRT1, sirtuin 1.

Cell Signaling Technology, Inc.), $\beta$-actin (cat. no. 4970; 1:1,000 dilution; Cell Signaling Technology, Inc.) and GAPDH (cat. no. 2118; 1:1,000 dilution; Cell Signaling Technology, Inc.). Subsequently, the membranes were incubated with an anti-rabbit secondary antibody conjugated with peroxidase (cat. no. ZB-5301; 1:5,000 dilution; OriGene Technologies, Inc.). Signals were detected using a chemiluminescent detection system (Pierce; Thermo Fisher Scientific, Inc.).

Statistical analysis. Values were presented as the mean \pm standard deviation. All data were analyzed using GraphPad Prism software (version no. 5; GraphPad Software, Inc.). Differences among $\geq 3$ groups were compared using one-way ANOVA followed by the Bonferroni post hoc test. $\mathrm{P}<0.05$ was considered to indicate a statistically significant difference. All experiments were performed three times.

\section{Results}

Sphk1/S1P signaling upregulates SIRT1 expression in leukemia cells. To explore the interaction between Sphk1/S1P and SIRT1 and signal integration in leukemia cells, SIRT1 expression was determined in K562 cells treated with S1P. Treatment of K562 cells with $0.5,1.0,1.5$ or $2.0 \mu \mathrm{M}$ S1P for $8 \mathrm{~h}$ significantly increased SIRT1 protein expression compared with the $0-\mu \mathrm{M}$ group (Fig. 1A). The time course of S1P-induced SIRT1 expression is presented in Fig. 1B. SIP significantly upregulated the protein levels of SIRT1 at 4 and $8 \mathrm{~h}$. Furthermore, treatment of K562 cells with 5, 10 or $20 \mu \mathrm{M}$ DMS, a Sphk1 inhibitor, significantly decreased SIRT1 expression compared with the $0-\mu \mathrm{M}$ group (Fig. 1C). Therefore, the results demonstrated that the Sphk1/S1p/SIRT1 axis is functional in leukemia cells and may serve an important role in regulating leukemogenesis.

SKI-II and EX527 inhibit leukemia cell growth. SKI-II is a novel specific inhibitor of Sphk (29) and EX527 is a specific inhibitor of SIRT1 (30). To explore the effect of Sphk1 and SIRT1 inhibition on the growth of leukemia cells, K562 and KCL22 cells were treated with various concentrations of SKI-II and EX527. Following incubation for $48 \mathrm{~h}$, cell proliferation was detected by CCK-8 assays. Treatment of K562 and KCL 22 cells with 5, 10 or $20 \mu \mathrm{M}$ SKI-II resulted in significant growth inhibition compared with the $0-\mu \mathrm{M}$ group (Fig. 2A). In contrast, EX527 treatment slightly inhibited the growth of 

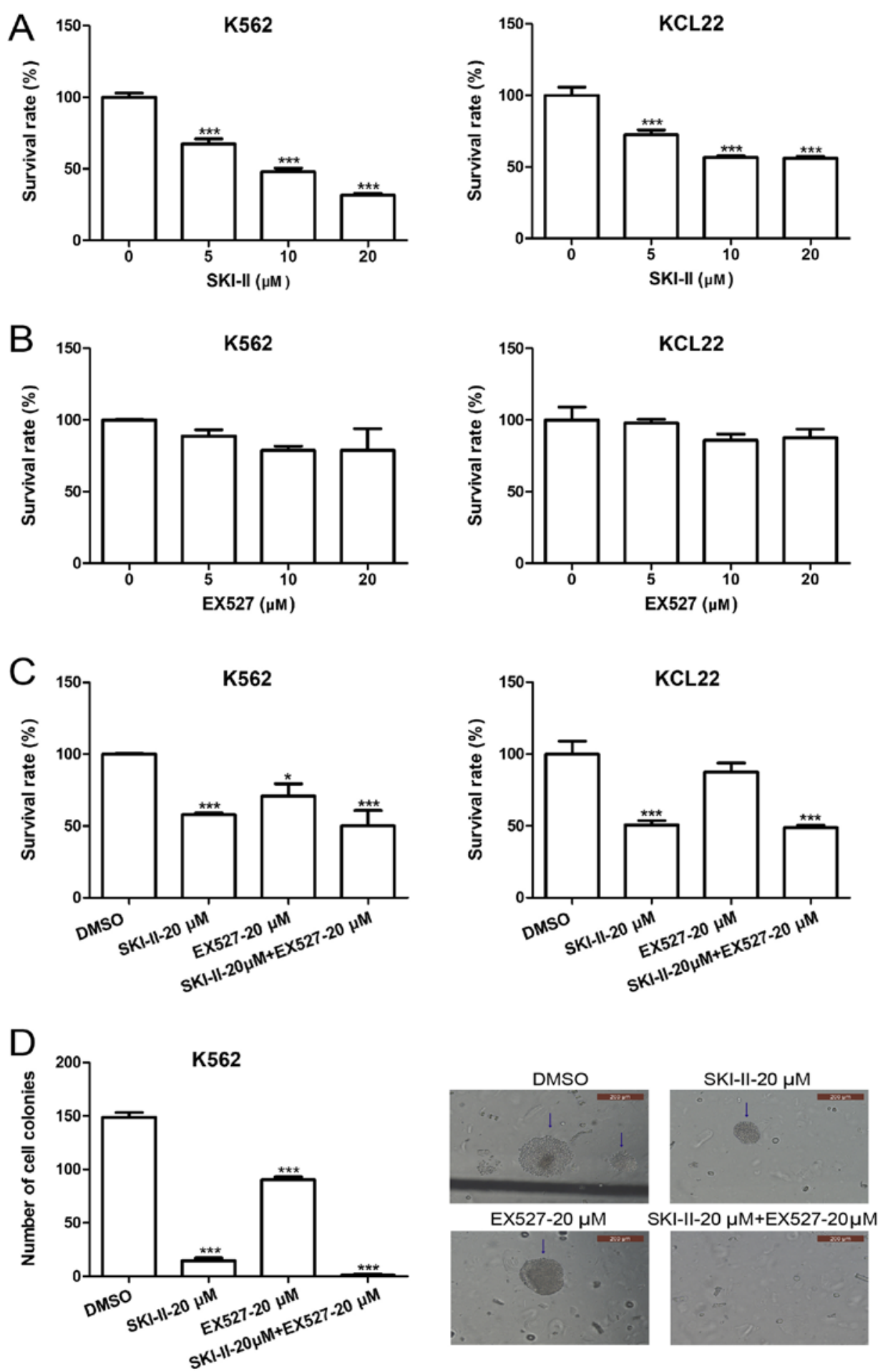

Figure 2. SKI-II and EX527 synergistically inhibit cell growth and colony formation in leukemia cells. (A) K562 and KCL22 cells were treated with SKI-II $(0,5,10$ or $20 \mu \mathrm{M})$ for $48 \mathrm{~h}$ and cell proliferation was determined by Cell Counting Kit-8 assays. (B) K562 and KCL22 cells were treated with EX527 (0, 5, 10 or $20 \mu \mathrm{M}$ ) for $48 \mathrm{~h}$. (C) K562 and KCL22 cells were treated with DMSO, $20 \mu \mathrm{M}$ SKI-II, $20 \mu \mathrm{M}$ EX527 or $20 \mu \mathrm{M}$ SKI-II $+20 \mu \mathrm{M}$ EX527 for $48 \mathrm{~h}$. (D) K562 cells were treated with DMSO, $20 \mu \mathrm{M}$ SKI-II, $20 \mu \mathrm{M}$ EX527 or $20 \mu \mathrm{M}$ SKI-II $+20 \mu \mathrm{M}$ EX527 for 7 days. The number of colonies ( $>50$ cells) was counted. under normal light at $\mathrm{x} 40$ magnification. Data are presented as the means \pm standard deviation. ${ }^{*} \mathrm{P}<0.05$ and ${ }^{* * * *} \mathrm{P}<0.001$ compared with $0 \mu \mathrm{M}$ or DMSO.

K562 and KCL22 cells; however, this inhibition was not significant (Fig. 2B). SKI-II-induced growth inhibition was enhanced by EX527 (Fig. 2C). Additionally, the effect of combined treatment with SKI-II and EX527 on the growth of leukemia cells was examined by evaluating the in vitro colony-forming ability of K562 cells. The results demonstrated that the number of cell colonies in the SKI-II and EX527 combined treatment group was significantly lower compared with the DMSO treatment group (Fig. 2D).

SKI-II and EX527 induce apoptosis in leukemia cells. The apoptosis-promoting effects of SKI-II and EX527 were observed. K562 and KCL22 cells were incubated with DMSO, $20 \mu \mathrm{M}$ EX527, $20 \mu \mathrm{M}$ SKI-II or $20 \mu \mathrm{M}$ EX527 

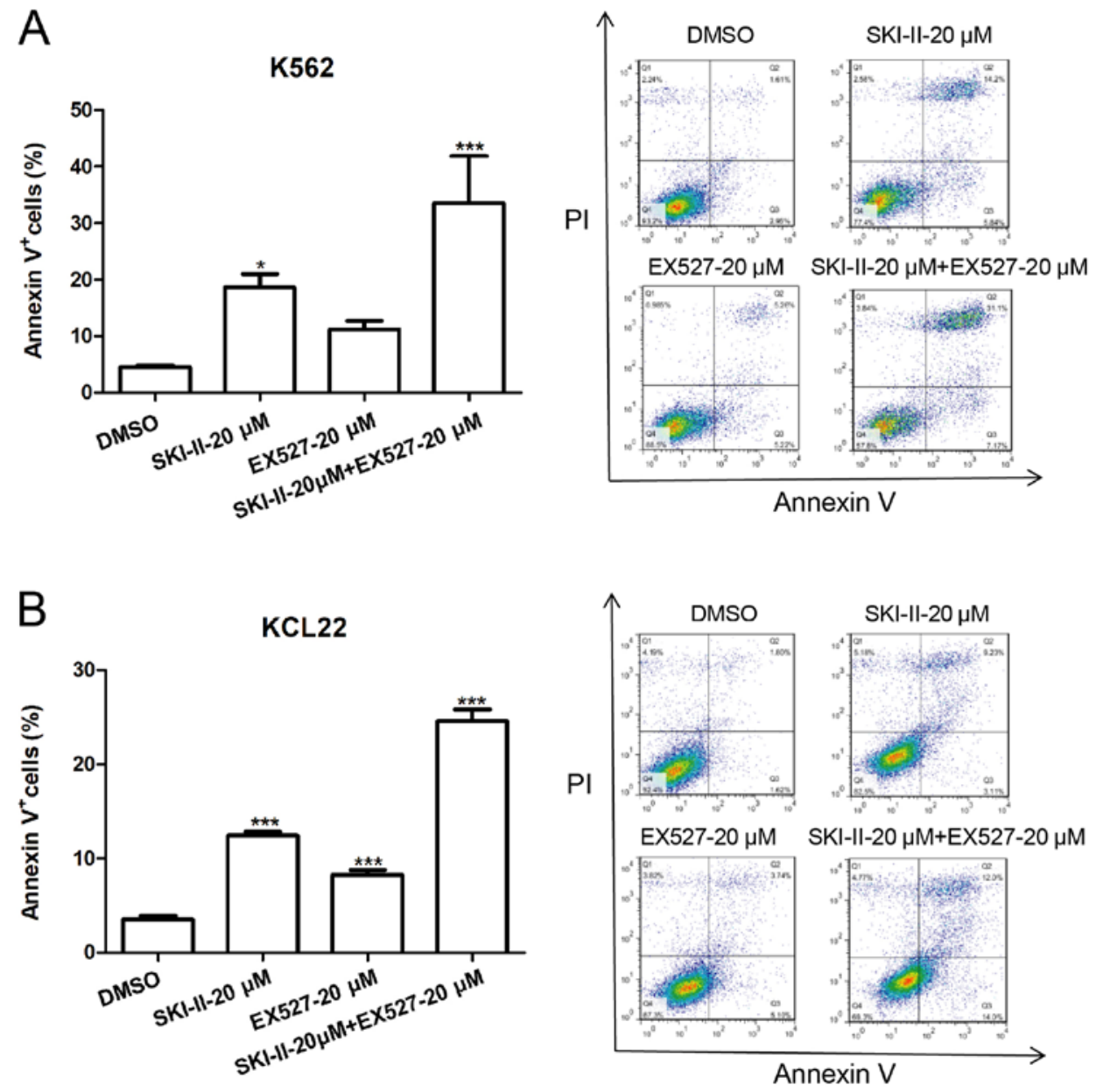

Figure 3. SKI-II and EX527 induce apoptosis arrest in leukemia cells. Apoptosis was analyzed by PI and Annexin V staining. (A) K562 cells were treated with DMSO, $20 \mu \mathrm{M}$ SKI-II, $20 \mu \mathrm{M}$ EX527 or $20 \mu \mathrm{M}$ SKI-II $+20 \mu \mathrm{M}$ EX527 for $24 \mathrm{~h}$. (B) KCL22 cells were treated with DMSO, $20 \mu \mathrm{M}$ SKI-II, $20 \mu \mathrm{M}$ EX527 or $20 \mu \mathrm{M}$ SKI-II $+20 \mu \mathrm{M}$ EX527 for $24 \mathrm{~h}$. Data are presented as the means \pm standard deviation. " $\mathrm{P}<0.05$ and ${ }^{* * * * *} \mathrm{P}<0.001$ compared with DMSO. PI, propidium iodide.

$+20 \mu \mathrm{M}$ SKI-II for $24 \mathrm{~h}$ and apoptosis was assessed. Treatment of K562 and KCL22 cells with $20 \mu \mathrm{M}$ SKI-II resulted in significant cell apoptosis, whereas treatment with EX527 moderately induced apoptosis of K562 and KCL22 cells, compared with the DMSO group (Fig. 3A and B). Furthermore, the combination of SKI-II and EX527 induced a significantly higher apoptosis rate compared with DMSO treatment group.

SKI-II and EX527 induce apoptosis and growth arrest in imatinib-resistant leukemia cells. To evaluate the effect of SKI-II and EX527 treatment on the growth of imatinib-resistant leukemia cells, TF-1-T315I cells were established by introducing a lentiviral vector encoding BCR-ABL1 (T315I). The mutant BCR-ABL transduction efficiency, as indicated by GFP expression, was $~ 93.4 \%$ (Fig. 4A). TF-1-T315I cells were treated with various concentrations of EX527 and SKI-II for $24 \mathrm{~h}$. Subsequently, cell growth was detected by CCK-8 assays and cell apoptosis was measured by Annexin V/PI assays. Both SKI-II and EX527 inhibited the proliferation of TF-1-T315I cells compared with the $0-\mu \mathrm{M}$ group (Fig. 4B and C). Furthermore, the combination treatment exhibited a marked synergistic growth-inhibiting effect on TF-1-T315I cells compared with the DMSO group (Fig. 4D). Moreover, the combination treatment with SKI-II and EX527 induced the lowest number of cell colonies (Fig. 4E) and a higher cell apoptosis rate (Fig. 5A) of TF-1-T315I cells compared to the DMSO group. Additionally, the cell cycle of TF-1-T315I cells was analyzed. Compared with the DMSO treatment, the combination of SKI-II and EX527 significantly increased the number of cells in the G0/G1 phase (Fig. 5B). This demonstrated that inhibition of SIRT1 and Sphk1 induced apoptosis and overcame imatinib resistance in leukemia cells.

SKI-II and EX527 inhibit ERK and STAT5 signaling in leukemia cells. To clarify the mechanism underlying the combined effects of SKI-II and EX527 on the growth and apoptosis of leukemia cells, SIRT1, p-ERK and p-STAT5 protein levels were analyzed in K562 (Fig. 6A-D) or TF-1-T315I (Fig. 7A-D) cells treated with DMSO, $20 \mu \mathrm{M}$ SKI-II, $20 \mu \mathrm{M}$ EX527 or $20 \mu \mathrm{M}$ SKI-II $+20 \mu \mathrm{M}$ EX527. The results demonstrated that combination treatment with SKI-II and EX527 had a synergistic inhibitory effect on the expression of SIRT1, p-ERK and p-STAT5 protein in K562 cells compared to the DMSO group. For TF-1-T315I cells, combination treatment with SKI-II and EX527 inhibited the expression of SIRT1 and p-STAT5 compared with the DMSO group. These results indicated that the STAT5 and ERK pathways were involved in the growth inhibition and death of leukemia cells treated with SKI-II and EX527. 

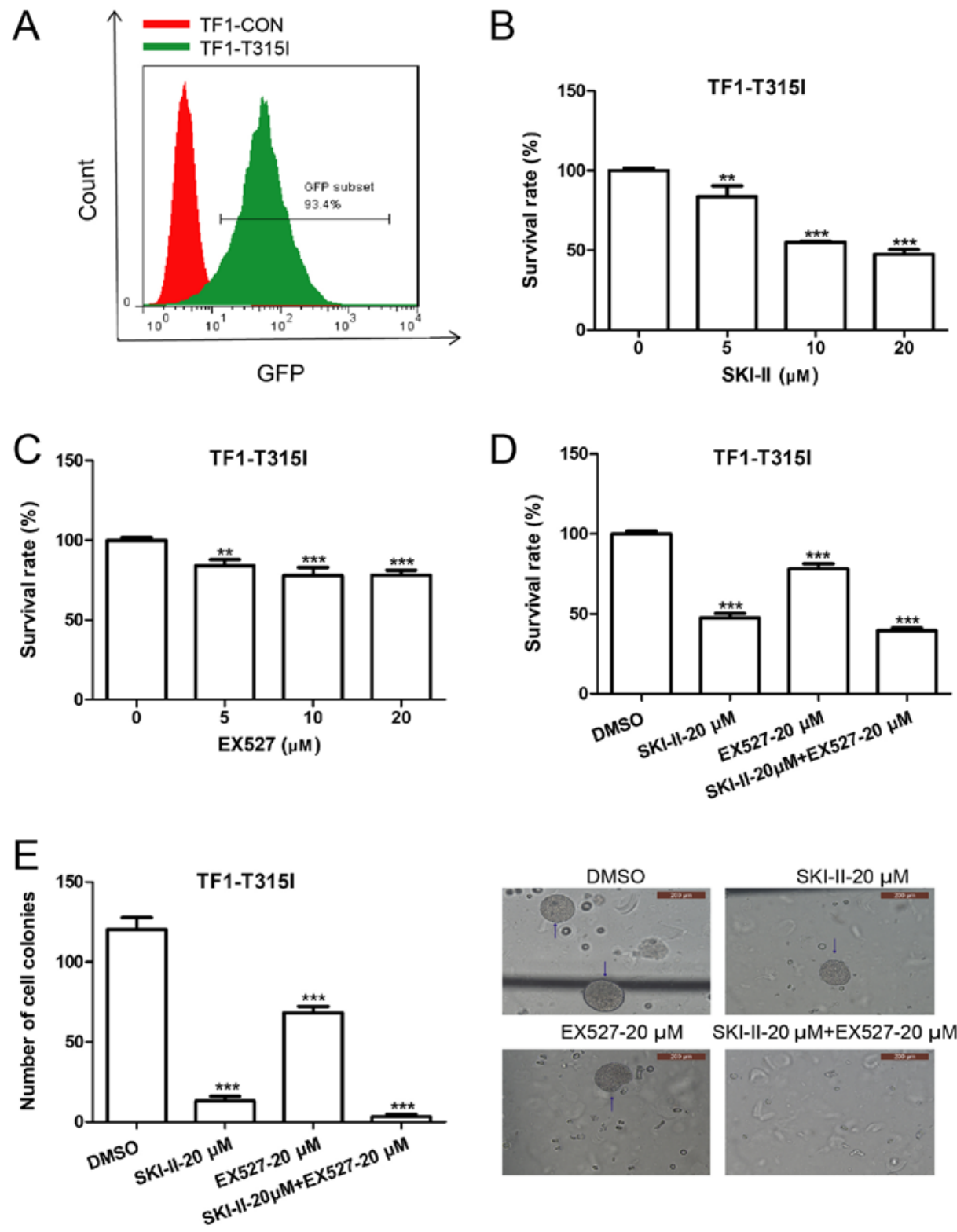

Figure 4. SKI-II and EX527 synergistically inhibit TF-1-T315I growth. (A) TF-1 cells were transduced with lentiviral vectors encoding BCR-ABL1 (T315I) and control vectors for $48 \mathrm{~h}$ and the transduction efficiency was determined by flow cytometry. Cell Counting Kit- 8 assays were used to determine cell proliferation in (B) TF-1-T315I cells treated with SKI-II $(0,5,10$ or $20 \mu \mathrm{M})$ for $24 \mathrm{~h}$, (C) TF-1-T315I cells treated with EX527 $(0,5,10$ or $20 \mu \mathrm{M})$ for $24 \mathrm{~h}$ and (D) TF-1-T315I cells treated with DMSO, $20 \mu \mathrm{M}$ SKI-II, $20 \mu \mathrm{M}$ EX527 or $20 \mu \mathrm{M}$ SKI-II $+20 \mu \mathrm{M}$ EX527 for $24 \mathrm{~h}$. (E) TF-1-T315I cells were treated with DMSO, $20 \mu \mathrm{M}$ SKI-II, $20 \mu \mathrm{M}$ EX527 or $20 \mu \mathrm{M}$ SKI-II $+20 \mu \mathrm{M}$ EX527 for 7 days and the number of colonies ( $>50$ cells) was counted under normal light at $\mathrm{x} 40$ magnification. Data are presented as the means \pm standard deviation. ${ }^{* *} \mathrm{P}<0.01$ and ${ }^{* * *} \mathrm{P}<0.001$ compared with $0 \mu \mathrm{M}$ or DMSO. CON, control.

\section{Discussion}

TKI therapy has markedly improved the long-term survival rates of patients with leukemia $(31,32)$. However, certain patients exhibit resistance to TKIs (33). Furthermore, the molecular mechanisms underlying TKI resistance in leukemia are not fully understood. Dysregulated lipid metabolism pathways have been considered to be novel targets for overcoming drug resistance in cancer therapy $(34,35)$. Sphk1, S1P and S1P receptors are key players in lipid metabolism signaling networks and their dysregulation contributes to tumorigenesis $(36,37)$. SIRT1 is an important regulator of genomic integrity and cell processes, including the cell cycle, DNA damage response, metabolism, apoptosis and autophagy (38). Considering CML cells constitutively express high levels of Sphk1 and SIRT1, the present study detected their interaction and integration in CML cells. The bioactive lipid S1P induced SIRT1 expression, while the inhibition of Sphk1 induced SIRT1 downregulation in leukemia cells. These data confirmed that the Sphk1/S1P/SIRT1 axis was active in leukemia cells. Since SIRT1 enhances the progression of leukemia and promotes drug resistance by increasing genetic instability (28), inhibition of SIRT1 was involved in the synergistic anti-leukemic effects of divalproex sodium and imatinib in CML cells (39). It has been hypothesized that targeting the Sphk1 and SIRT1 pathways may have synergistic inhibitory effects on leukemia cell growth and drug resistance.

Considering stable transfection of Sphk shRNA induced cell death (13), the present study used chemical inhibitors to explore the effects of Sphk1 and SIRT1 inhibition on the 

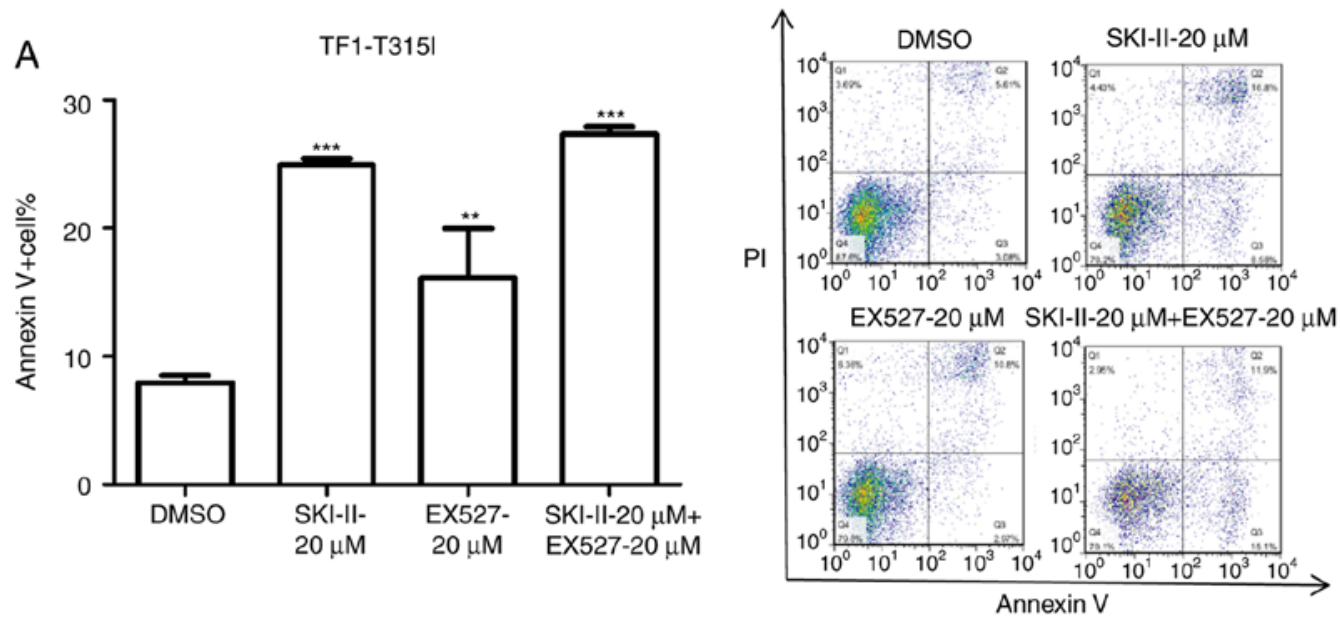

B

TF1-T3151
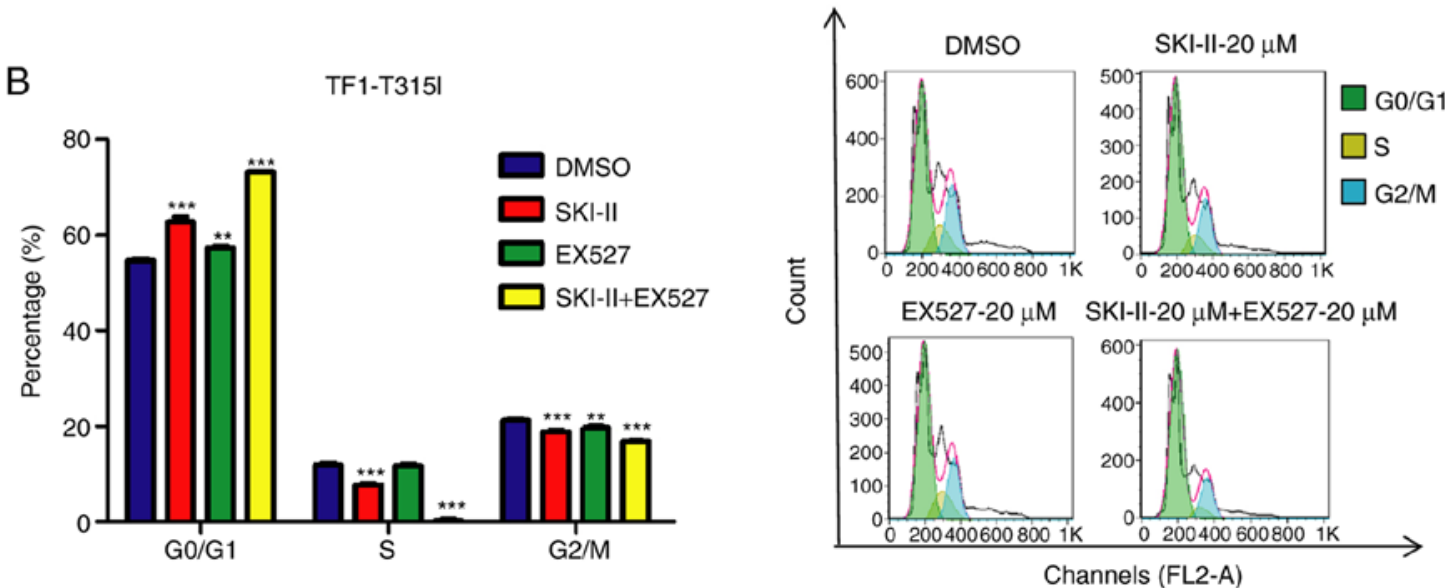

Figure 5. SKI-II and EX527 induce apoptosis and cell cycle arrest in TF-1-T315I cells. TF-1-T315I cells were treated with DMSO, $20 \mu \mathrm{M} \mathrm{SKI-II,} 20 \mu \mathrm{M}$ EX527 or $20 \mu \mathrm{M}$ SKI-II $+20 \mu \mathrm{M} \mathrm{EX527}$ for $24 \mathrm{~h}$ and (A) apoptosis and (B) cell cycle distribution were analyzed. Data are presented as the means \pm standard deviation. ${ }^{* *} \mathrm{P}<0.01$ and ${ }^{* * *} \mathrm{P}<0.001$ compared with DMSO. PI, propidium iodide.

A

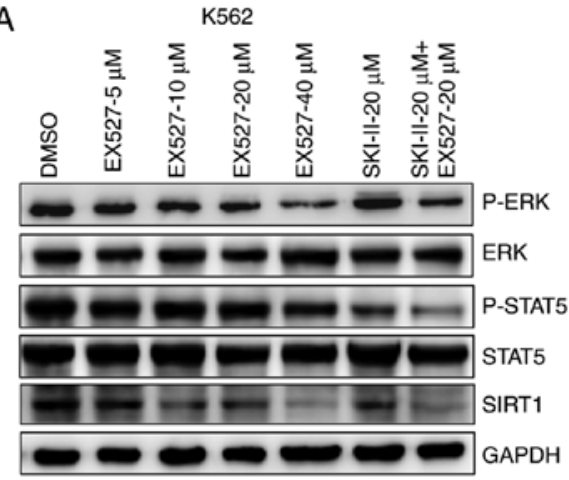

C

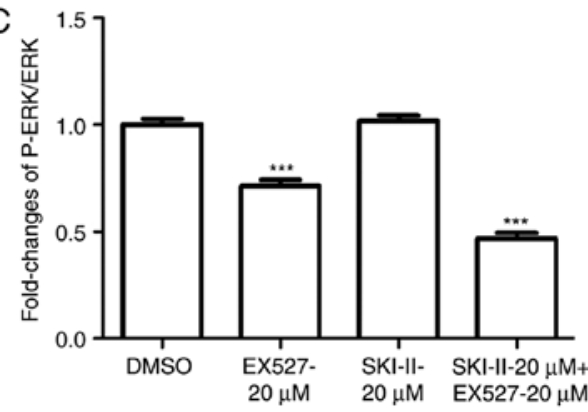

B

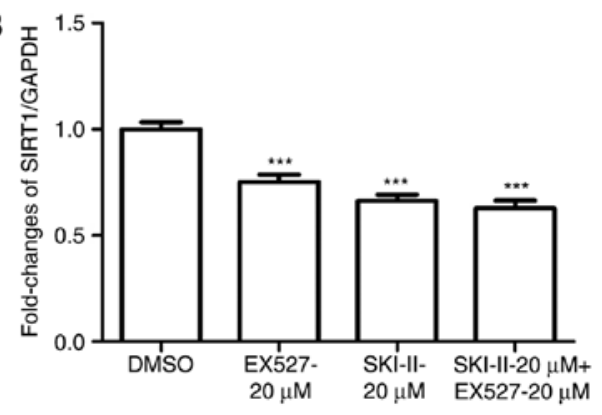

D

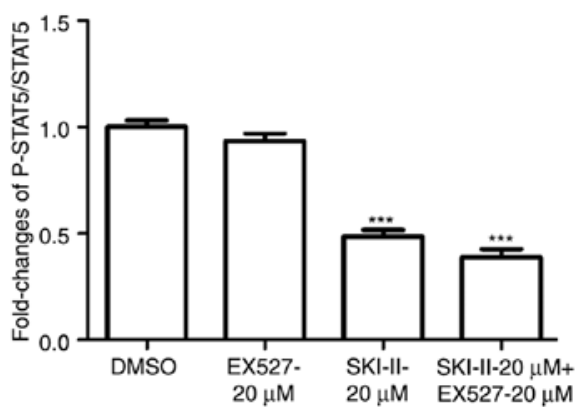

Figure 6. Inhibition of sphingosine kinase 1 and SIRT1 leads to inactivation of ERK and STAT5 in leukemia cells. (A) K562 cells were treated with DMSO, EX527 $(5,10,20$ or $40 \mu \mathrm{M})$, SKI-II $(20 \mu \mathrm{M})$ or SKI-II $(20 \mu \mathrm{M})+$ EX527 $(20 \mu \mathrm{M})$ for $24 \mathrm{~h}$ and various protein levels were evaluated by western blotting. The protein levels of (B) SIRT1, (C) p-ERK/ERK and (D) p-STAT5/STAT5 in K562 cells were quantified. Data are presented as the means \pm standard deviation. ${ }_{* * * *} \mathrm{P}<0.001$ compared with DMSO. SIRT1, sirtuin $1 ; \mathrm{p}-$, phosphorylated. 
A
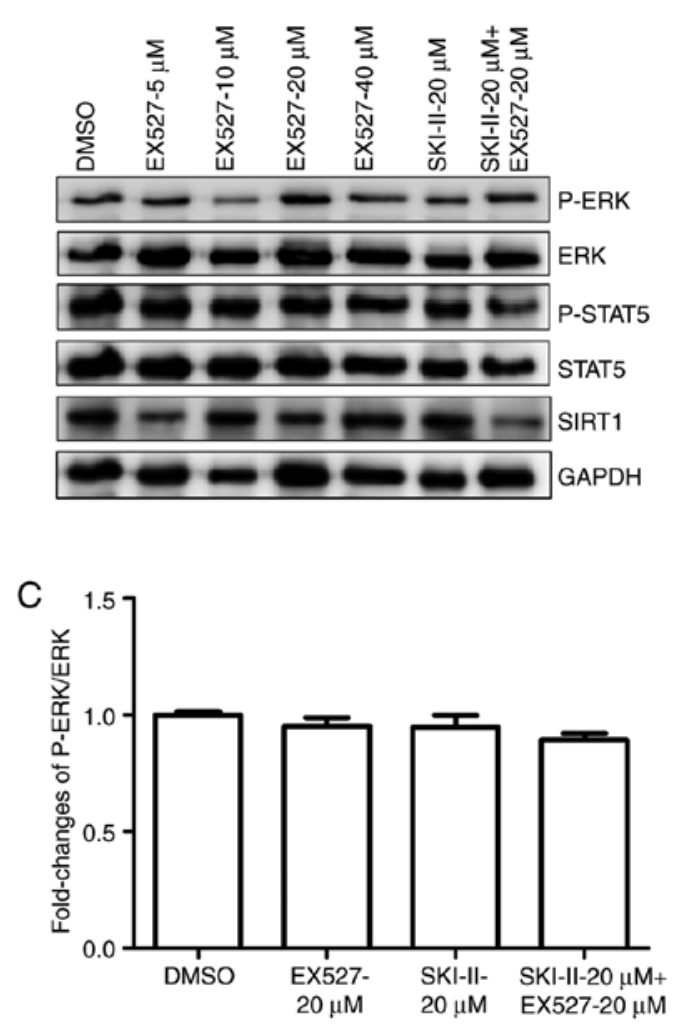
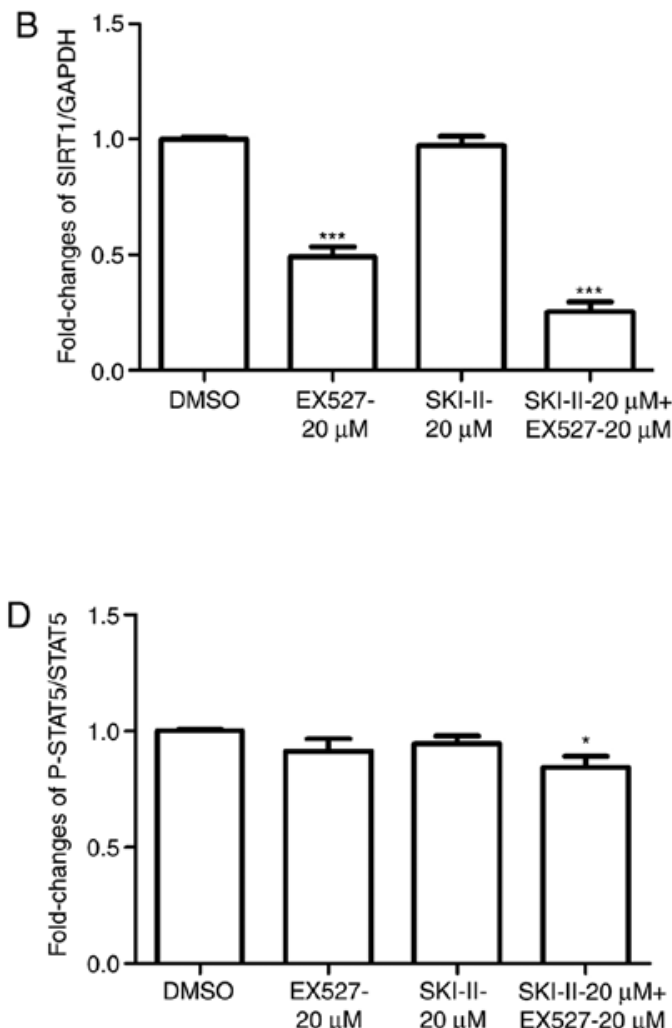

Figure 7. Inhibition of sphingosine kinase 1and SIRT1 induces the inactivation of ERK and STAT5 in leukemia cells. (A) TF-1-T315I cells were treated with DMSO, EX527 $(5,10,20$ or $40 \mu \mathrm{M})$, SKI-II $(20 \mu \mathrm{M})$ or SKI-II $(20 \mu \mathrm{M})+$ EX527 $(20 \mu \mathrm{M})$ for $24 \mathrm{~h}$ and various protein levels were evaluated by western blotting. The protein levels of (B) SIRT1, (C) p-ERK/ERK and (D) p-STAT5/STAT5 in TF-1-T315I cells were quantified. Data are presented as the mean \pm standard deviation. ${ }^{*} \mathrm{P}<0.05$ and ${ }^{* * * *} \mathrm{P}<0.001$ compared with DMSO. SIRT1, sirtuin 1.

growth and survival of leukemia cells. Treatment of K562 and KCL22 cells with SKI-II, a highly selective, non-ATP-competitive Sphk1 inhibitor (29), reduced cell viability, inhibited cell proliferation and induced apoptosis. EX527 is a potential novel and specific small-molecule inhibitor of SIRT1 activity (30). EX527 had a modest suppressive effect on the growth of leukemia cells; however, in combination with SKI-II, EX527 exhibited a synergistic inhibitory effect on cell growth and a synergistic positive effect on apoptosis in leukemia cells. Furthermore, the cell cycle changes of K562 and KCL22 cells were examined. Unfortunately, the cycle data of each cell line did not provide consistent results across experimental repeats, as such the cell cycle data for these two cell lines was omitted from the present study. However, the combination of SKI-II and EX527 significantly increased the percentage of the G0/G1 phase in TF-1-T315I cells. SKI-II inhibits the growth of acute myelogenous leukemia cells in vitro and in vivo (40) and the combination of EX527 with SKI-II exhibited synergistic anti-leukemic activity, which could possibly be therapeutically exploited.

TKI therapies are rendered ineffective due to the survival of leukemia stem cells and drug resistance (41). Primitive quiescent CML stem cells are particularly resistant to imatinib-induced apoptosis (42). Since Sphk1/S1P signaling is dysregulated by stimuli originating from tumor microenvironments, the inhibition of this pathway is crucial in overcoming TKI resistance in leukemia cells $(11,19)$. T315I is the most frequent mutation causing imatinib resistance in patients with advanced CML or $\mathrm{Ph}^{+}$acute lymphocytic leukemia (43). It has been demonstrated that targeting Sphk1 and SIRT1 individually enhanced the sensitivity to TKI in various cancer cells, including acute myeloid leukemia, CML, renal cancer and lung adenocarcinoma $(25,27,44,45)$, indicated its potential as a novel agent for the treatment of TKI-resistant leukemia. The present study lacked data on the treatment for leukemia cells with TKI in combination with SKI-II and EX527.

Although SKI-II and EX527 exhibited significant suppressive effects on the growth of leukemia cells, their mechanisms remain unknown. SKI-II treatment reduced SIRT1 protein levels and presented cytotoxic effects in leukemia cells. Since constitutively active STAT5 and MAPK/ERK signaling have been demonstrated in CML cell lines and primary CML CD34 ${ }^{+}$cells $(46,47)$, STAT5 and MAPK/ERK appears to be a critical determinant of the TKI sensitivity of CML progenitor cells $(48,49)$. Combined treatment with SKI-II and EX527 decreased SIRT1, p-ERK and p-STAT5 levels in K562 cells. Furthermore, the combination treatment inhibited SIRT1 and p-STAT5 expression in TF-1-T31rI. Considering EX527 exhibited a marked inhibitory effect on SIRT1 expression, the combined effect with SKI-II was not apparent over that of EX527 treatment alone. Occasionally, p-ERK expression demonstrated an inhibitor-induced feedback regulation in K562 cells; however, this effect was not evident in TF-1-T315I cells. Therefore, the suppression of the ERK and STAT5 pathways may contribute to SKI-II and EX527-induced apoptosis and growth arrest in leukemia cells. 
In conclusion, the present study confirmed a novel axis in leukemias cells in which Sphk1/S1P signaling mediated SIRT1 upregulation. Inhibition of Sphk1 and SIRT1 exhibited synergistic suppressive effects on growth and overcame leukemias TKI resistance. Therefore, targeting the Sphk1/S1P/SIRT1 axis may be a novel therapeutic strategy for the treatment of leukemia.

\section{Acknowledgements}

Not applicable.

\section{Funding}

The present study was partially supported by the Key R\&D Project of Shandong Province (grant no. 2019GSF108144).

\section{Availability of data and materials}

The datasets used and/or analyzed during the current study are available from the corresponding author on reasonable request.

\section{Authors' contributions}

LW conceived and designed the present study. YL, YG, BL and $\mathrm{WN}$ performed the experiments. YL, YG, BL, LZ and LW were involved in the acquisition, analysis and/or interpretation of data. YL and LW wrote the manuscript. YL, YG, BL and LW reviewed and edited the manuscript. All authors read and approved the final manuscript.

\section{Ethics approval and consent to participate}

Not applicable.

\section{Patient consent for publication}

Not applicable.

\section{Competing interests}

The authors declare that they have no competing interests.

\section{References}

1. Kumari A, Brendel C, Hochhaus A, Neubauer A and Burchert A Low BCR-ABL expression levels in hematopoietic precursor cells enable persistence of chronic myeloid leukemia under imatinib. Blood 119: 530-539, 2012.

2. O'Hare T, Deininger MW, Eide CA, Clackson T and Druker BJ: Targeting the BCR-ABL signaling pathway in therapy-resistant Philadelphia chromosome-positive leukemia. Clin Cancer Res 17: 212-221, 2011.

3. Corbin AS, Agarwal A, Loriaux M, Cortes J, Deininger MW and Druker BJ: Human chronic myeloid leukemia stem cells are insensitive to imatinib despite inhibition of BCR-ABL activity. J Clin Invest 121: 396-409, 2011

4. Cilloni D and Saglio G: Molecular pathways: BCR-ABL. Clin Cancer Res 18: 930-937, 2012.

5. Sattler M and Griffin JD: Molecular mechanisms of transformation by the BCR-ABL oncogene. Semin Hematol 40 (Suppl 2): S4-S10, 2003.

6. Sinclair A, Latif AL and Holyoake TL: Targeting survival pathways in chronic myeloid leukemia stem cells. Br JPharmacol 169: $1693-1707,2013$
7. Liu Q, Luo Q, Halim A and Song G: Targeting lipid metabolism of cancer cells: A promising therapeutic strategy for cancer. Cancer Lett 401: 39-45, 2017.

8. Tang X, Benesch MG and Brindley DN: Lipid phosphate phosphatases and their roles in mammalian physiology and pathology. J Lipid Res 56: 2048-2060, 2015.

9. Patmanathan SN, Wang W, Yap LF, Herr DR and Paterson IC: Mechanisms of sphingosine 1-phosphate receptor signalling in cancer. Cell Signal 34: 66-75, 2017.

10. Tabasinezhad M, Samadi N, Ghanbari P, Mohseni M, Saei AA, Sharifi S, Saeedi N and Pourhassan A: Sphingosin 1-phosphate contributes in tumor progression. J Cancer Res Ther 9: 556-563, 2013.

11. Nagahashi M, Takabe K, Terracina KP, Soma D, Hirose Y, Kobayashi T, Matsuda Y and Wakai T: Sphingosine-1-phosphate transporters as targets for cancer therapy. Biomed Res Int 2014: 651727, 2014.

12. Mendelson K, Evans T and Hla T: Sphingosine 1-phosphate signalling. Development 141: 5-9, 2014.

13. Gao Z, Wang H, Xiao FJ, Shi XF, Zhang YK, Xu QQ, Zhang XY, Ha XQ and Wang LS: SIRT1 mediates Sphk1/S1P-induced proliferation and migration of endothelial cells. Int J Biochem Cell Biol 74: 152-160, 2016.

14. Li QF, Wu CT, Guo Q, Wang H and Wang LS: Sphingosine 1-phosphate induces Mcl-1 upregulation and protects multiple myeloma cells against apoptosis. Biochem Biophys Res Commun 371: 159-162, 2008.

15. Evangelisti C, Evangelisti C, Buontempo F, Lonetti A, Orsini E, Chiarini F, Barata JT, Pyne S, Pyne NJ and Martelli AM: Therapeutic potential of targeting sphingosine kinases and sphingosine 1-phosphate in hematological malignancies. Leukemia 30: 2142-2151, 2016.

16. Li QF, Huang WR, Duan HF, Wang H, Wu CT and Wang LS: Sphingosine kinase-1 mediates BCR/ABL-induced upregulation of Mcl-1 in chronic myeloid leukemia cells. Oncogene 26: 7904-7908, 2007.

17. Salas A, Ponnusamy S, Senkal CE, Meyers-Needham M, Selvam SP, Saddoughi SA, Apohan E, Sentelle RD, Smith C, Gault CR, et al: Sphingosine kinase-1 and sphingosine 1-phosphate receptor 2 mediate Bcr-Abl1 stability and drug resistance by modulation of protein phosphatase 2A. Blood 117: 5941-5952, 2011.

18. Baran Y, Salas A, Senkal CE, Gunduz U, Bielawski J, Obeid LM and Ogretmen B: Alterations of ceramide/sphingosine 1phosphate rheostat involved in the regulation of resistance to imatinib-induced apoptosis in K562 human chronic myeloid leukemia cells. J Biol Chem 282: 10922-10934, 2007.

19. Ricci C, Onida F, Servida F, Radaelli F, Saporiti G, Todoerti K, Deliliers GL and Ghidoni R: In vitro anti-leukaemia activity of sphingosine kinase inhibitor. Br J Haematol 144: 350-357, 2009.

20. Marfe G, Di Stefano C, Gambacurta A, Ottone T, Martini V, Abruzzese E, Mologni L, Sinibaldi-Salimei P, de Fabritis P, Gambacorti-Passerini C, et al: Sphingosine kinase 1 overexpression is regulated by signaling through PI3K, AKT2, and mTOR in imatinib-resistant chronic myeloid leukemia cells. Exp Hematol 39: 653-665, 2011.

21. Powell JA, Lewis AC, Zhu W, Toubia J, Pitman MR, Wallington-Beddoe CT, Moretti PA, Iarossi D, Samaraweera SE, Cummings $\mathrm{N}$, et al: Targeting sphingosine kinase 1 induces MCL1-dependent cell death in acute myeloid leukemia. Blood 129: 771-782, 2017.

22. Sobue S, Nemoto S, Murakami M, Ito H, Kimura A, Gao S, Furuhata A, Takagi A, Kojima T, Nakamura M, et al: Implications of sphingosine kinase 1 expression level for the cellular sphingolipid rheostat: Relevance as a marker for daunorubicin sensitivity of leukemia cells. Int J Hematol 87: 266-275, 2008.

23. Vachharajani VT, Liu T, Wang X, Hoth JJ, Yoza BK and McCall CE: Sirtuins link inflammation and metabolism. J Immunol Res 2016: 8167273, 2016.

24. Roth M, Wang Z and Chen WY: Sirtuins in hematological aging and malignancy. Crit Rev Oncog 18: 531-547, 2013.

25. Li L, Osdal T, Ho Y, Chun S, McDonald T, Agarwal P, Lin A, Chu S, Qi J, Li L, et al: SIRT1 activation by a c-MYC oncogenic network promotes the maintenance and drug resistance of human FLT3-ITD acute myeloid leukemia stem cells. Cell Stem Cell 15: 431-446, 2014.

26. Zhou L, Wang Q, Chen X, Fu L, Zhang X, Wang L, Deng A, Li D, Liu J, Lv N, et al: AML1-ETO promotes SIRT1 expression to enhance leukemogenesis of $t(8 ; 21)$ acute myeloid leukemia. Exp Hematol 46: 62-69, 2017. 
27. Li L, Wang L, Li L, Wang Z, Ho Y, McDonald T, Holyoake TL, Chen W and Bhatia R: Activation of p53 by SIRT1 inhibition enhances elimination of CML leukemia stem cells in combination with imatinib. Cancer Cell 21: 266-281, 2012.

28. Li L and Bhatia R: Role of SIRT1 in the growth and regulation of normal hematopoietic and leukemia stem cells. Curr Opin Hematol 22: 324-329, 2015.

29. Giusto K, Patki M, Koya J, Ashby CR Jr, Munnangi S, Patel K and Reznik SE: A vaginal nanoformulation of a SphK inhibitor attenuates lipopolysaccharide-induced preterm birth in mice. Nanomedicine (Lond) 14: 2835-2851, 2019.

30. Wang T, Li X and Sun SL: EX527, a Sirt-1 inhibitor, induces apoptosis in glioma via activating the p53 signaling pathway. Anticancer Drugs 31: 19-26, 2020.

31. Peters GJ: From 'targeted therapy' to targeted therapy. Anticancer Res 39: 3341-3345, 2019.

32. Bhalla S, Tremblay D and Mascarenhas J: Discontinuing tyrosine kinase inhibitor therapy in chronic myelogenous leukemia: Current understanding and future directions. Clin Lymphoma Myeloma Leuk 16: 488-494, 2016.

33. Holyoake TL and Vetrie D: The chronic myeloid leukemia stem cell: Stemming the tide of persistence. Blood 129: 1595-1606, 2017.

34. Gao Y, Gao F, Chen K, Tian ML and Zhao DL: Sphingosine kinase 1 as an anticancer therapeutic target. Drug Des Devel Ther 9: 3239-3245, 2015

35. Wallington-Beddoe CT, Bradstock KF and Bendall LJ Oncogenic properties of sphingosine kinases in haematological malignancies. Br J Haematol 161: 623-638, 2013.

36. Shida D, Takabe K, Kapitonov D, Milstien S and Spiegel S: Targeting SphK1 as a new strategy against cancer. Curr Drug Targets 9: 662-673, 2008

37. Xie Z, Liu H and Geng M: Targeting sphingosine-1-phosphate signaling for cancer therapy. Sci China Life Sci 60: 585-600, 2017.

38. Qiu G, Li X, Che X, Wei C, He S, Lu J, Jia Z, Pang K and Fan L: SIRT1 is a regulator of autophagy: Implications in gastric cancer progression and treatment. FEBS Lett 589: 2034-2042, 2015.

39. Wang W, Zhang J, Li Y, Yang X, He Y, Li T, Ren F, Zhang J and Lin R: Divalproex sodium enhances the anti-leukemic effects of imatinib in chronic myeloid leukemia cells partly through SIRT1. Cancer Lett 356: 791-799, 2015.

40. Yang L, Weng W, Sun ZX, Fu XJ, Ma J and Zhuang WF: SphK1 inhibitor II (SKI-II) inhibits acute myelogenous leukemia cell growth in vitro and in vivo. Biochem Biophys Res Commun 460 903-908, 2015.
41. Braun TP, Eide CA and Druker BJ: Response and resistance to BCR-ABL1-targeted therapies. Cancer Cell 37: 530-542, 2020.

42. Holtz MS, Forman SJ and Bhatia R: Nonproliferating CML $\mathrm{CD} 34+$ progenitors are resistant to apoptosis induced by a wide range of proapoptotic stimuli. Leukemia 19: 1034-1041, 2005.

43. Roche-Lestienne $\mathrm{C}$ and Preudhomme C: Mutations in the ABL kinase domain pre-exist the onset of imatinib treatment. Semin Hematol 40 (Suppl 2): S80-S82, 2003.

44. Zhang L, Wang X, Bullock AJ, Callea M, Shah H, Song J, Moreno K, Visentin B, Deutschman D, Alsop DC, et al: Anti-S1P antibody as a novel therapeutic strategy for VEGFR TKI-resistant renal cancer. Clin Cancer Res 21: 1925-1934, 2015.

45. Sun J, Li G, Liu Y, Ma M, Song K, Li H, Zhu D, Tang X, Kong $\mathbf{J}$ and Yuan X: Targeting histone deacetylase SIRT1 selectively eradicates EGFR TKI-resistant cancer stem cells via regulation of mitochondrial oxidative phosphorylation in lung adenocarcinoma. Neoplasia 22: 33-46, 2020.

46. Kaymaz BT, Selvi N, Gündüz C, Aktan C, Dalmızrak A, Saydam G and Kosova B: Repression of STAT3, STAT5A, and STAT5B expressions in chronic myelogenous leukemia cell line K-562 with unmodified or chemically modified siRNAs and induction of apoptosis. Ann Hematol 92: 151-162, 2013.

47. Chorzalska A, Ahsan N, Rao RSP, Roder K, Yu X, Morgan J, Tepper A, Hines S, Zhang P, Treaba DO, et al: Overexpression of Tpl2 is linked to imatinib resistance and activation of MEK-ERK and $\mathrm{NF}-\kappa \mathrm{B}$ pathways in a model of chronic myeloid leukemia. Mol Oncol 12: 630-647, 2018.

48. Schafranek L, Nievergall E, Powell JA, Hiwase DK, Leclercq T, Hughes TP and White DL: Sustained inhibition of STAT5, but not JAK2, is essential for TKI-induced cell death in chronic myeloid leukemia. Leukemia 29: 76-85, 2015.

49. Nambu T, Araki N, Nakagawa A, Kuniyasu A, Kawaguchi T, Hamada A and Saito H: Contribution of BCR-ABL-independent activation of ERK1/2 to acquired imatinib resistance in K562 chronic myeloid leukemia cells. Cancer Sci 101: 137-142, 2010.

This work is licensed under a Creative Commons Attribution-NonCommercial-NoDerivatives 4.0 International (CC BY-NC-ND 4.0) License. 